\title{
Turistik Bir Ürün Olan Maraş Dondurmasının Dondurma Üreticileri Tarafından Değerlendirilmesi
}

\author{
Ahmet ÇAVUŞ ${ }^{l}$ \& Zafer TÜRKMENDA $\breve{G}^{2}$ \& Kaan GÜLDO $\breve{G} A N^{3}$
}

Öz

Türkiye'de dondurma denilince ilk akla gelen ve coğrafi işareti olan Maraş dondurmasının üretici bakış açısıyla irdelenmesi gelişimi için önemlidir. Bu bağlamda çalışmada Kahramanmaraş ili sınırları içerisinde faaliyet gösteren dondurma üreticisi firmalarının yapısal özellikleri, üretim ve pazarlama durumları ile sorunları ele alınmıştır. Dondurma üretimi gerçekleştiren dokuz işletme yöneticisine yarı yapılandırılmış görüşme formu ile mülakat yapılmıştır. Sonuç olarak, üreticilerin, Maraş dondurmasını tanıtıcı ve turistik bir değer olarak gördüğü, en çok Arap ülkelerine ihracat yaptıkları, üretim ve pazarlama inovasyonu gerçekleştirdikleri, tümünün HACCP belgesine sahip olduğu ve nitelikli personel temini sorunu yaşadıkları tespit edilmiştir.

Anahtar Kelimeler: Maraş dondurması, Turistik ürün, Coğrafi işaret, Kahramanmaraş

\section{An Evaluation of Maraş Ice-cream as a Touristic Product by Ice-cream Producers}

\begin{abstract}
It is important for its development to examine from the producer's point of view of Maras ice cream which is the first ice cream that springs to mind and has geographical indication in Turkey. In this context, the structural features, production, marketing and problems of the ice cream producer firms operating within the boundaries of Kahramanmaras province were discussed. Nine business managers who were involved in ice cream production were interviewed by a semi-structured interview form. As a result, it has been determined that the producers see Maras ice cream as an advertiser and touristic value, they mostly export to Arab countries, realize production and marketing innovations, all have HACCP certificate and they experience qualified personnel supply problems.
\end{abstract}

Keywords: Maras ice cream, Tourist product, Geographical indication, Kahramanmaras

\footnotetext{
${ }^{1}$ Doç. Dr., Atatürk Üniversitesi, Turizm Fakültesi, ahmetcavus@ atauni.edu.tr

${ }^{2}$ Arş. Gör., Atatürk Üniversitesi, Turizm Fakültesi, zafer.turkmendag@ atauni.edu.tr

${ }^{3}$ Kaan.guldogan@hotmail.com
} 


\section{Giriş}

Dondurma günümüz dünyasının en çok tüketilen gıdalarından birisi ve özellikle sıcak iklimlerin yaşandığı yerler için sadece bir gıda değil aynı zamanda serinleme aracıdır. Dondurmanın tarihi çok eskilere dayanmakla birlikte yapımı ve tüketimi belirli bölgelerde olabiliyordu fakat bugün teknolojinin gelişimi ve dondurma kültürünün yaygınlaşması ile tüm dünyada üretilebilen ve tüketilebilen bir gastronomik ürün olarak karşımıza çıkmaktadır. Kullanılan hammaddeler ve yapılış şekli, dondurmanın kalitesini ve lezzetini etkilemektedir. Öyle ki bu farkl1l1klar ve üründeki değişim nedeniyle tüketiciler gerçek dondurma lezzetini aramaktadır. Böylece tanınırlığı artan dondurma üretildiği kent için de bir marka halini almaya başlamaktadır. Kahramanmaraş denilince insanların aklına ilk olarak dondurmanın gelmesi, bu ürün ile Kahramanmaraş kentinin özdeşleştiğini gösterir. Dondurma, Kahramanmaraş için çok önemli bir imaj öğesi olarak kabul edilebilir (Zeren ve Gül, 2013).

Araştırmanın amacı Kahramanmaraş ili sınırları içerisinde faaliyet gösteren dondurma işletmelerinin üretim durumlarını, yapısal özelliklerini, Maraş dondurmasının turistik ürün olarak değerlendirmelerini ve sorunlarını ortaya koymaktır.

\section{Kavramsal Çerçeve}

Maraş dondurması keçi sütü ve orkide bitkisi kullanılarak üretilen ülkemizde yaygın olarak tüketilen ve bazı ülkelere ihracatı yapılan turistik bir üründür. Günümüzde dondurmanın esas tadını korumak için Kahramanmaraş ilinde üretim yapılmakta ve dondurularak başka şehir ve ülkelere gönderilmektedir. Yöre için coğrafi işaret alan Maraş dondurması zamanla kentin simgesi haline gelmiş, sağladığı ticari gelir, istihdam ve turizm geliriyle bölge için kalkınma aracı olmuştur. Dünya dondurma sektöründe ise ilk beş ülke, ABD, Avustralya, Norveç, İsveç, Danimarka'dır. Türkiye'de dondurmanın uzun yıllar bir tatlı çeşidi olarak algılanmaması ve sadece yazın yenen serinletici bir yiyecek olarak sunulması nedeniyle dünya ortalamasının altında bir tüketim söz konusu olmuştur. ABD'de kişi başına yıllık dondurma tüketimi 25 litre, Kuzey Avrupa ülkelerinde 20 litre, Avrupa'da 8-10 litre, Türkiye'de ise 1 litre dolayındadır. Ancak son yıllarda tüketiminin tüm mevsimlere yayılmaya başlaması ve talebin her geçen yıl artması da sektörün gelişime açık bir yapı sergilemesini sağlamaktadır (Özel ve Ceylan, 2016).

Dondurma ile ilgili olarak Tarım ve Orman Bakanlığı (TOB) ve Türk Standartları Enstitüsünün (TSE) yayımlanmış mevzuatları mevcuttur. TOB tarafından yayımlanan Türk Gıda Kodeksi Yönetmeliği altında Yenilebilir Buzlu Ürünler Tebliği ve Dondurma Tebliği bu konuda iki mevzuat olarak göze çarpmaktadır: Dondurma Tebliğine göre dondurma karışımı, "İçerisinde tat ve çeşidine göre, süt ve/veya süt ürünlerini, içme suyu, şeker ve izin verilen katkı maddelerini bulunduran, istenildiğinde salep, yumurta ve/veya yumurta ürünleri, aroma maddeleri ve çeşni maddeleri gibi bileşenleri içeren, henüz dondurulmamış haldeki karışım ürününü, ifade eder" denilmektedir (TSE, 2010, s.19). Maraş dondurması; Maraş dondurması tekniğine göre üretilen, şeker, süt, salep ve/veya izin 
verilen diğer katkı maddelerinin katılmasıyla üretilen bir üründür. Maraş dondurmasında, keçi sütü ve salebin kullanılması büyük önem taşımaktadır (Kaya, Karabekmez Erdem ve Tekin, 2017).

Maraş dondurması, Kahramanmaraş ili sınırları içinde yetişen kekik, keven, sümbül ve çiğdem gibi çiçeklerle beslenen keçilerin eşsiz kıvam ve aromaya sahip sütleri ile salebin dondurma ustalarının mahir ellerinde benzersiz bir lezzete ulaştırılması ile elde edilir. Maraş dondurması, tamamen Anadolu topraklarına özgü köklü bir lezzet kültürünün ürünü olup, sadece Kahramanmaraş’ta üretilebilmektedir. Maraş dondurmasının üretimi, işlenmesi ve diğer işlemlerin tamamı Kahramanmaraş ili sınırları içerisinde gerçekleşmek zorundadır. Keçi sütü üreticisinden temin edilen sütlerin soğuk zincir kırılmadan ve genel uygulamada sağımın üzerinden dört saat geçmeden Maraş dondurması üretim yerine (işletme olarak anılacaktır) ulaştırılması gerekmektedir. İşletmeye gelen keçi sütü ön filtrelemeden geçtikten sonra sütün pH'si analiz edilir, içerisinde su olup olmadığının tespiti yapılır. Maraş dondurması yapımında \%100 keçi sütü kullanılır. Paketlenip satışa hazır hale getirilmiş olan Maraş dondurması, $-20^{\circ} \mathrm{C}^{\prime}$ den daha yüksek sıcaklıklara maruz kalmadığ 1 sürece bir y1l süre ile muhafaza edilebilir (Türk Patent ve Marka Kurumu, 2017).

\section{Yöntem}

$\mathrm{Bu}$ çalışmada nitel araştırma yöntemi benimsenmiştir. Kahramanmaraş’ta dondurma üretimi yapan dokuz işletme yöneticisi ile mülakat yapılarak veriler elde edilmiştir. Görüşmeler yarı yapılandırılmış bir form ile gerçekleştirilmiştir. Formdaki sorular üreticilerin demografik özellikleri, üretim metotları, üretim istatistikleri, üretim standartları ve pazarlama yöntemlerine yöneliktir. Görüşmeler 2018 yılı Nisan ayı içerisinde yapılmıştır. Araştırmanın odaklandığı temel problem, coğrafi işaretli Maraş dondurmasının üretim ve pazarlama süreçlerinin nasıl gerçekleştirildiğidir. Bu bağlamda katılımcılara yöneltilen demografik soruların yanı sıra yarı yapılandırılmış form şu soruları içermektedir: Maraş dondurması coğrafi işaretli bir ürün müdür? Turizm sektöründe dondurmanın turistik bir ürün olduğunu düşünüyor musunuz? Ülkeye gelen turistlerin Maraş dondurması hakkında fikirleri olduğunu düşünüyor musunuz? Kaç çeşit dondurma üretimi yapıyorsunuz? En fazla tercih edilen ürün hangisidir? En fazla hangi şehirlere dondurma gönderiyorsunuz? Hangi aylarda daha çok dondurma satıyorsunuz? Hangi aylarda daha çok dondurma üretiyorsunuz ve ortalama mevsimlere göre aylık dondurma üretiminiz ne kadardır? İhracat yapıyor musunuz? Hangi ülkelere ihracat yapıyorsunuz? İnovasyon'a (yenileşme) yönelik planlarınız ve çalışmalarınız var mı? Maraş dondurması üretiminde geleneksel üretim mi teknolojik üretim mi sizin için daha avantajlı? Maraş dondurmasında katkı maddesi kullanıyor musunuz? Ürettiğiniz ürünlere keçi sütünden başka süt kullanıyor musunuz? İşletmenize ait bir keçi çiftliğiniz var mı? Ürünleriniz için malzeme teminini hangi ilçeden, ilden yada ülkeden sağlıyorsunuz? Ürettiğiniz ürünleri başka şehir veya ülkelere nasıl ulaştırıyorsunuz? İşletmenizde Maraş dondurması üretimi için sertifika veya belge var mı? Hangi belgeye sahipsiniz? HACCP, İSO belgesi gibi belgeleriniz var mı? Maraş dondurmasının il turizmine daha fazla katkı sunması için neler yapılmalıdır? Maraş dondurması yapımı ve satımında karşılaştığınız sorunlar nelerdir? 


\section{Bulgular}

Araştırmaya katılan Maraş dondurması işletmecilerinin ikisi ortaokul (\%22,2), üçü lise (\%33,3), ikisi önlisans $(\% 22,2)$ ve ikisi lisans $(\% 22,2)$ mezunudur. İşletmelerde kişi sayılarına göre \%55,5'i 5-50 kişi, \%11,1'i 51-100 kişi ve \%33,3’üu ise 101 ve üzeri kişi çalıştığını beyan etmiştir. İşletmelerin beşinin web sitesinin olduğu fakat birinin internet üzerinden satış yaptığı yanıtı alınmıştır (Tablo 1).

Tablo 1. Mülakat yapılan Maraş dondurması üreticilerinin demografik özellikleri.

\begin{tabular}{|l|c|c|c|}
\hline & & \multicolumn{2}{|c|}{ işletmeci } \\
\hline Cinsiyet & Kadın & 1 & 11,1 \\
\hline Yaş & Erkek & 8 & 88,9 \\
\hline & $19-25$ & 2 & 22,1 \\
\hline & $26-32$ & 1 & 11,2 \\
\hline Medeni Hâl & $33-40$ & 2 & 22,2 \\
\hline & $41-50$ & 1 & 11,1 \\
\hline
\end{tabular}

Araştırmanın bulgularına göre katılımcıların yedisi coğrafi işaretli ürünün tanımını yapabilmiştir. Katılımcıların tamamı ise Maraş dondurmasının coğrafi işaretli bir ürün ve turizm sektörü için önemli olduğunu ayrıca ülkeye gelen turistlerin Maraş dondurması hakkında fikirlerinin olduğunu düşünmektedir. İşletmelerin \% 44,4'ü 20-50 çeşit, \%33,3’ü 50 ile 100 çeşit ve \%22,2'i ise 100 ve üzeri çeşit dondurma üretmektedir. En fazla tercih edilen ürün ise $\% 88,8$ 'i sade dondurma derken bir tanesi sade-fıstıklı dondurmanın daha çok tercih edildiğini söylemiştir. İşletmelerin dondurma gönderdiği başlica şehirler İstanbul (\%88,8), Ankara (\%55,5), İzmir (\%55,5), Antalya $(\% 44,4)$, Adana $(\% 33,3)$ ve Mersin $(\% 33,3)$ illeri ön sıralarda yer almaktadır. Ayrıca işletmelerin biri tüm Büyükşsehirlere ve biri de tüm İç Anadolu'daki illere gönderim yapmaktadır (Tablo 2). Maraş dondurmasının en fazla nisan ve eylül ayları arasında üretimi ve satışı yapılmaktadır. 
Tablo 2. Dondurma gönderilen yurtiçindeki iller ve yüzdeleri.

\begin{tabular}{|l|c|c|}
\hline Gönderilen il & Gönderen İșletme Sayısı & $\%$ \\
\hline İstanbul & 8 & 85,8 \\
\hline Ankara & 5 & 55,5 \\
\hline İzmir & 5 & 44,4 \\
\hline Antalya & 4 & 33,3 \\
\hline Adana & 3 & 33,3 \\
\hline Mersin & 3 & 22,2 \\
\hline Antep & 2 & 22,2 \\
\hline Bursa & 2 & 11,1 \\
\hline Aydın & 1 & 11,1 \\
\hline Muğla & 1 & 11,1 \\
\hline Samsun & 1 & 5 \\
\hline
\end{tabular}

Üreticiler en fazla ihracatı Katar (\%66,7), Avrupa ülkeleri $(\% 55,6)$, Birleşik Arap Emirlikleri $(\% 33,3)$ ve Irak’a $(\% 33,3)$ yapmaktadır. Dışsatımdaki ülkeler incelendiğinde daha çok yakın coğrafyaya ve genel olarak ise tüm kıtalara gönderim yapıldığı görülmektedir (Tablo 3).

Tablo 3. Dondurma ihracatı yapılan ülkeler ve yüzdeleri.

\begin{tabular}{|c|c|c|}
\hline Gönderilen Ülke & Gönderen İşletme Sayısı & $\%$ \\
\hline Katar & 6 & 66,7 \\
\hline Avrupa & 5 & 55,6 \\
\hline Birleşik Arap Emirlikleri & 3 & 33,3 \\
\hline Irak & 3 & 33,3 \\
\hline Suudi Arabistan & 2 & 22,2 \\
\hline Çin & 2 & 22,2 \\
\hline Kuveyt & 2 & 22,2 \\
\hline$A B D$ & 1 & 11,1 \\
\hline Avustralya & 1 & 11,1 \\
\hline Azerbaycan & 1 & 11,1 \\
\hline Bahreyn & 1 & 11,1 \\
\hline Bulgaristan & 1 & 11,1 \\
\hline Gürcistan & 1 & 11,1 \\
\hline İran & 1 & 11,1 \\
\hline İsrail & 1 & 11,1 \\
\hline Kanada & 1 & 11,1 \\
\hline Kazakistan & 1 & 11,1 \\
\hline
\end{tabular}




\begin{tabular}{|l|c|c|}
\hline Kıbrıs & 1 & 11,1 \\
\hline Mısır & 1 & 11,1 \\
\hline Suriye & 1 & 11,1 \\
\hline Ürdün & 1 & 11,1 \\
\hline
\end{tabular}

İşletmelerin tamamının inovasyon yaptığı ve özellikle üretim sürecinde ve pazarlamada inovasyon yaptıkları görülmüştür. Ayrıca üç işletmenin Ar-Ge, iki işletmenin ise hizmet ve ürün inovasyonu yaptığı görülmüş̧ür (Tablo 4).

Tablo 4. İşletmelerin inovasyon çalışmaları.

\begin{tabular}{|l|c|c|}
\hline & İşletme Sayısı & $\%$ \\
\hline Üretim Sürecinde İnovasyon & 7 & 77,7 \\
\hline Pazarlama İnovasyonu & 7 & 77,7 \\
\hline Ar-Ge & 3 & 33,3 \\
\hline Hizmet İnovasyonu & 2 & 22,2 \\
\hline Ürün Inovasyonu & 2 & 22,2 \\
\hline
\end{tabular}

Üreticilerin üçte ikisi teknolojik üretimin geleneksel üretimden daha avantajlı olduğunu düşünmektedir. İşletmelerin altısı üretimde keçi sütünden başka süt kullanmamakta, tamamı katkı maddesi kullanmamakta ve beşi ise keçi çiftliğine sahiptir. Dondurma yapımında kullanılan malzemenin büyük bir bölümü ülke içerisinden sağlamaktadırlar. Malzeme temininde ilk sırayı Gaziantep alırken, Adana, İstanbul ve Kahramanmaraş bu ili takip etmektedir. Hammadde temin edilen tek ülke İtalya'dır (Tablo 5, Şekil 1).

Tablo 5. Maraş dondurması için malzeme tedarik edilen iller ve ülkeler

\begin{tabular}{|l|c|c|}
\hline iller & İșletme Sayısı & $\%$ \\
\hline Gaziantep & 8 & $88,8 \%$ \\
\hline Adana & 4 & $44,4 \%$ \\
\hline İstanbul & 4 & $4,4 \%$ \\
\hline Kahramanmaraş & 4 & $44,4 \%$ \\
\hline İtalya & 4 & $22,2 \%$ \\
\hline Ankara & 2 & $11,1 \%$ \\
\hline İzmir & 2 & $11,1 \%$ \\
\hline
\end{tabular}




\begin{tabular}{|c|c|c|}
\hline Kastamonu & 1 & $11,1 \%$ \\
\hline Kayseri & 1 & $11,1 \%$ \\
\hline Şanlıurfa & 1 & $11,1 \%$ \\
\hline
\end{tabular}

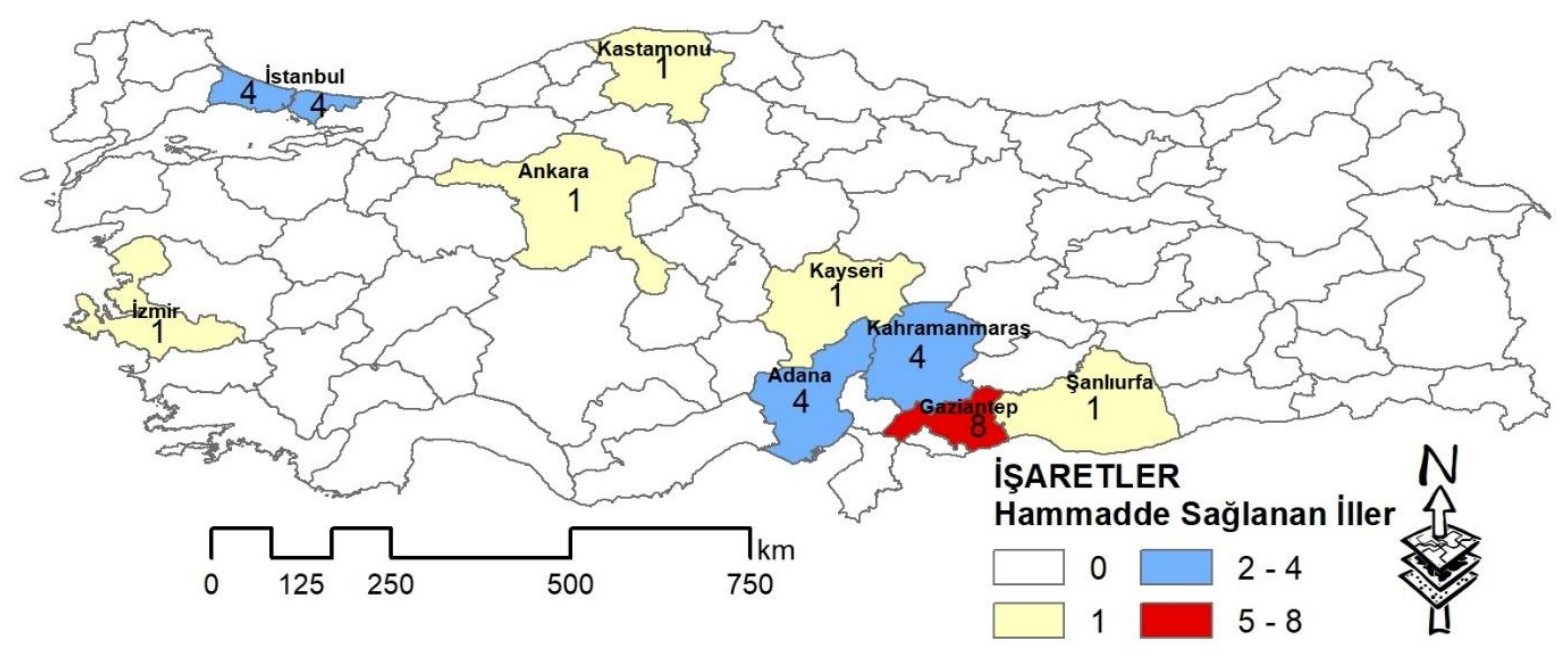

Şekil 1. Maraş dondurması imalatında malzeme tedarik edilen iller ve işletme sayıları

Üreticilerin \%55,6'sı dağıtımlarında sadece frigorifik araçlar ile gönderim yaparken \%22,2'si ise gemi ve şoklama sistemini de kullanmaktadır (Tablo 6).

Tablo 6. Dondurma dağıtımında kullanılan araçlar

\begin{tabular}{|l|c|c|} 
& İşletme sayısı & $\%$ \\
\hline Sadece frigorifik araçlar & 5 & 55,6 \\
\hline Gemi & 2 & 22,2 \\
\hline Şoklama sistemi & 2 & 22,2
\end{tabular}

Üreticilerin tamamının HACCP ve İSO gibi hijyen ve kalite belgelerinden en az birisine sahip olduğu tespit edilmiştir. Bu belgeler arasında özellikle ISO 2001, ISO 22000 belgeleri ile ISO 9001 ve ISO 9003 belgeleri bulunmaktadır. İşletmelerin sahip oldukları diğer standart belgeler helal sertifikası, BRC, TSE, GIMDES, NISSERT, MEYER ve IFCE'dir (Tablo 7). 
Tablo 7. Maraş Dondurması işletmelerinin sahip olduğu kalite ve hijyen belgeleri

\begin{tabular}{|l|c|c|}
\hline Belge Türü & işletme sayısı & $\%$ \\
\hline HACCP & 9 & 100 \\
\hline ISO 2001 & 7 & 77,7 \\
\hline Helal Sertifikası & 3 & 33,3 \\
\hline ISO 22000 & 3 & 33,3 \\
\hline BRC & 2 & 22,2 \\
\hline ISO 9001 & 1 & 11,1 \\
\hline ISO 9003 & 1 & 11,1 \\
\hline TSE & 1 & 11,1 \\
\hline GIMDES & 1 & 11,1 \\
\hline NISSERT & 1 & 11,1 \\
\hline MEYER & 1 & 11,1 \\
\hline IFCE & 1 & 11,1 \\
\hline
\end{tabular}

Katılımcıların "Maraş dondurmasının il turizmine daha fazla katkı sunması için neler yapılmalıdır?" sorusuna verdikleri yanıtlarda ilk olarak Maraş dondurmasının tanıtım ve reklamının daha etkili yapılması gerektiğini vurgulamışlardır. Bunun yanında festival, şenlik, TV programları, fuarlar, altyapı ve işbirliği yapılması gerektiği de belirtilmişlerdir (Tablo 8).

Tablo 8. İşletmelerin Maraş dondurmasının il turizm hareketliliğine katkısının arttırılmasına yönelik görüşleri

\begin{tabular}{|l|c|c|}
\hline & işletme sayısı & $\%$ \\
\hline Etkili tanıtım ve reklam & 6 & 66,6 \\
\hline Festival, şenlik ve fuar gibi etkinlikler arttırılmalı & 3 & 33,3 \\
\hline Altyapı geliștirilmeli & 1 & 11,1 \\
\hline isșletmeler arası işbirliği arttırılmalı & 1 & 11,1
\end{tabular}

İşletmeler en çok eğitimli personel eksikliği sorunu yaşamaktadırlar. İşletmelerin uzun süre deneyimli personeli tutamadığ 1 veya yüksek eğitim almış kişileri sektöre çekmede sorun yaşadıklarını dile getirmişlerdir. Bunun yanı sıra sahip oldukları diğer sorunlar misafirlerin personellere yönelik kötü davranışları, yeterli tanıtım ve reklamın yapılamaması ve ulaşım sorunudur (Tablo 9). 
Tablo 9. İşletmelerin karşılaştıkları sorunlar

\begin{tabular}{|l|c|c|}
\hline & işletme sayısı & $\%$ \\
\hline Eğitimli (nitelikli) personel & 4 & 44,4 \\
\hline Misafir yaklaşımı problemleri & 2 & 22,2 \\
\hline Tanıtım ve reklam & 1 & 11,1 \\
\hline Ulașım & 1 & 11,1 \\
\hline
\end{tabular}

\section{Sonuç ve Tartışma}

Maraş dondurması ülkemizde yaygın olarak tüketilen ve bazı ülkelere ihracatı yapılan turistik bir üründür. Günümüzde dondurmanın esas tadını korumak için Kahramanmaraş ilinde üretim yapılmakta ve dondurularak başka şehir ve ülkelere gönderilmektedir. Yöre için coğrafi işaret alan Maraş dondurması zamanla kentin simgesi haline gelmiş, sağladığı ticari gelir, istihdam ve turizm geliriyle bölge için kalkınma araçlarından biri olmuştur. Karademir, Kaya Sandal ve Urhan (2018) tarafından yapılan bir araştırmada "Maraş dondurması turizm için önemlidir” yargısına eğitim düzeyine bakmaksızın tüm katılımcıların \%84,4'ü katılıyorum veya kesinlikle katılıyorum cevabını vermiştir. Türkiye'de coğrafi işarete sahip ve ismini dondurma ile duyuran Kahramanmaraş’taki dondurma işletmelerinin yapısal özellikleri üretim durumları ve pazarlama yöntemleri gibi özelliklerinin incelendiği bu araştırma Maraş dondurmasının tüketiciye ulaşmasındaki süreci daha ayrıntılı tanımamızı sağlamaktadır.

Üreticiler, Kahramanmaraş dondurmasının coğrafi işaretli bir ürün olarak ilin tanıtımı ve turizm hareketlerine olumlu katkısı olduğunu düşünmektedirler. İşletmelerin yurtiçinde daha çok büyükşehirlere, yurtdışında ise en çok Arap, Ortadoğu ve Avrupa ülkelerine dondurma sattıkları ve ulaştırmada daha çok frigorifik araçları kullandıkları tespit edilmiştir. Üretimde hijyen ve sağlık tedbirlerine önem veren işletmeler katkı maddesi kullanmamaya dikkat etmektedirler.

İşletmelerin tümünün HACCP sistemine sahip olması hijyen ve sağlık konusuna önem verildiğinin bir yansımasıdır. Tüketicinin hijyen beklentilerinin karşılanması ve özellikle süt ürünlerinin ciddi sağlık sorunları oluşturabildiği dikkate alındığında işletmelerin bu konudaki farkındalığının yüksek olması Maraş dondurmasının imajına katkı sağlamaktadır. Aynı şekilde Kahramanmaraş ilinde turizme hizmet sunan pastane işletmelerinde çalışan geleneksel Maraş dondurması üretim personelinin hijyen ve gıda güvenliğine ilişkin uygulama düzeyinin de tıpkı bilgi düzeyi gibi "yüksek" seviyede olduğu tespit edilmiştir (Giritlioğlu ve Kızılcık, 2016).

Maraş dondurması üretiminde en çok karşılaşılan nitelikli personel eksikliği tüm sektörün neredeyse ortak sorunu olarak görülmektedir. Sektörde maaşların düşük olması, imaj kaygısı, zor çalışma şartları gibi nedenlerle eğitimli kişiler sektörü tercih etmemektedir. Ayrıca sektörde zaman içerisinde deneyim kazanmış olan kişiler uzun süre sektörde çalışmaya devam etmemektedir. Bunun 
önlenmesi için eğitim kurumlarında ilgili bölümlerin açılması ve çalışma şartlarının iyileştirilmesi gerekmektedir. Ayrıca bu eğitimler kapsamında coğrafi işaret bilincini arttırıcı eğitim iç̧eriklerinin geliştirilmesi de önem arz etmektedir.

Maraş dondurmasının pazarlamasının arttırılması için işletmeler daha fazla tanıtım ve reklam yapılması ve ayrıca fuar, festival gibi etkinliklerin de gerçekleştirilmesi gerektiği önerisinde bulunmaktadır. Buna göre Kahramanmaraş Büyükşehir Belediyesi tarafından 2017 y1lında birincisi düzenlenen Uluslararası Dondurma Kültür ve Sanat Festivali gibi festivallerin farklı illerde de yapılarak tanıtımın daha etkin yapılması sağlanmalıdır. Dünyanın birçok yerinde uluslararası dondurma fuarlarında Maraş dondurmasının temsiliyetinin arttırılması da devlet teşvikleri ile desteklenebilir.

Üreticilerin yurtdışına ihracatlarını daha çok frigorifik araçlar ile yaptıkları göz önüne alındığında taşıma maliyetleri yüksek olduğundan Maraş dondurması üreticilerinin özellikle lojistik alanında Ar-Ge ve inovasyona önem vermeleri gerekmektedir. Maraş dondurmasının yurtdışında tanıtımı ve satışı ayrıca ülke tanıtımını da sağlayarak turist hareketliliğini de etkileyecektir.

\section{Kaynakça}

Bars, T. ve Akbay, C. (2013). “Kahramanmaraş İlinde Süt ve Süt Ürünleri İşleyen Mandıra İşletmelerinin Yapısal Analizi”, KSÜ Doğa Bilimleri Dergisi, 16(2), 9-20.

Bars, T. ve Akbay, C. (2016). "Kahramanmaraş İlinde Dondurma İşletmelerinin Yapısal Analizi”, TEAD, 2(2), $35-45$.

Çavuş, A., (2010). Gastronomi Turizmi Açısından Akçaabat Köftesi ve Trabzon'daki Turistik Aktiviteye Katkısı. Uluslaraarası Doğu Karadeniz Turizm Sempozyumu Bildiriler Kitabı, 184-199.

Doğanay, H. Zaman, S., (2016). Türkiye Turizm Coğrafyası. Pegem Akademi Yayınları.

Dayısoylu, K. S., Yörükoğlu, T. ve Ançel, T. (2017). "Kahramanmaraş'ın Coğrafi İşaretli Ürünleri ve İlin Potansiyel Durumu", KSÜ Doğa Bilimleri Dergisi, 20(1), 80-88.

Giritlioğlu, İ ve Kızılcık, O. (2016). "Turizme Hizmet Sunan Pastane İşletmelerinde Çalışan Dondurma Üretim Personelinin Hijyen Ve Gıda Güvenliğine İlişkin Bilgi ve Uygulama Düzeyi Üzerine Bir Araştırma”, Mehmet Akif Ersoy Üniversitesi Sosyal Bilimler Enstitüsü Dergisi, 8(15), 301-319.

Karademir, N., Kaya Sandal, E. ve Urhan, F. B. (2018). “Kahramanmaraş’ta Turizm Algısı”, Doğu Coğrafya Dergisi, 23(39), 45-64.

Kaya, E., Karabekmez Erdem, T. ve Tekin, F. B. (2017). "Maraş Dondurması Üretimi ve Üretilen Dondurmanın Fizikokimyasal Niteliklerinin Belirlenmesi", Caucasian Journal of Science, 45-56.

Özel, G. ve Ceylan, R. (2016). "Dondurma Tüketimi Tercihini Etkileyen Özelliklerin Konjoint Analizi ile Belirlenmesi", The Journal of Operations Research, Statistics, Econometrics and Management Information Systems, 4(2), 147-158.

Şimşek, O., Tuncay, İ. ve Bilgin, B. (2006). "Endüstriyel Dondurma Üretiminde Farklı Stabilizatör Kullanımının Dondurma Kalitesine Etkisi”, Tekirdağ Ziraat Fakültesi Dergisi, 3/1, 55-63.

Tiryaki, G. Y. ve Akbay, C. (2009). "Kahramanmaraş'ta Dondurma Tüketim Alışkanlığı”, GIDA, 34(3), 143148.

Türk Patent ve Marka Kurumu (2017). "Resmi Coğrafi İşaret ve Geleneksel Ürün Adı Bülteni”, Sayı 5, Ankara.

Uludă̆, P. (2009). “Türkiye'de Dondurma Sektörü, Tüketici Eğilimleri Ve Firmalar Arası Rekabet”, Yayınlanmamış Yükseklisans Tezi, Namık Kemal Üniversitesi Fen Bilimleri Enstitüsü, Tekirdağ. 
Uzmay, A., Koyubenbe, N. ve Konca, Y. (2006). "İzmir İlinde Süt ve Süt Ürünleri İşleyen ve Pazarlayan İşletmelerin Bazı Özellikleri Üzerine Bir Araştırma”, Ege Üniversitesi Ziraat Fakültesi Dergisi, 43/3, 43-53.

Zaman, S. ve Kayserili, A. (2015). “The Role Of Geographical Signs In Gastronomy Tourism: A Case Study Of Erzurum Cag Kebap”. International Journal Of Academic Research In Enviriment And Geography, 2(1), 40-45., Doi: 10.6007/IJAREG/v2-i1/1878 (Yayin No: 1655351)

Zeren, H. E. ve Gül, S. (2013). “Kent İmajının Markalaşmaya Etkisi: Kahramanmaraş Örneği”, Journal of Social and Humanities Sciences Research, 3(2), 1-26. 